\title{
THE ACTION OF MORPHINE AND RELATED SUBSTANCES ON CONTRACTION AND ON ACETYLCHOLINE OUTPUT OF COAXIALLY STIMULATED GUINEA-PIG ILEUM
}

\author{
BY \\ W. D. M. PATON \\ From the Department of Pharmacology, Royal College of Surgeons of England, London
}

(RECEIVED DECEMBER 21, 1956)

\begin{abstract}
Morphine depresses the twitch and tetanus of stimulated guinea-pig ileum by reducing acetylcholine released from cholinergic nerve endings. Acetylcholine output per shock falls to roughly the same residual amount at varying stimulation rates. Since normal output per shock declines with increasing stimulus frequency, the proportionate effect of morphine diminishes as stimulus frequency rises. Acute "tolerance" to morphine and a state of "morphinedependence" can be produced. Phenadoxone, dihydromorphinone, metopon, methadone, and heroin are more active, codeine and pethidine less active, than morphine. Nalorphine also depresses the twitch and can desensitize the gut both to itself and to morphine.
\end{abstract}

Despite the widespread use of morphine there is still no agreement as to the mode of action, either when used as an analgesic or for depressing the activity of the intestine. It has been suggested that its anticholinesterase activity causes the central actions; but it is a relatively feeble inhibitor of cholinesterase, and much more active inhibitors do not reproduce its effects. On the intestine, attention has focused on morphine's ability either to depress propulsion, or to increase the tone of the gut. An investigation of the action of opiates on intestinal loops in the dog by Vaughan Williams and Streeten $(1950,1951)$ has clarified some apparent contradictions in previous experimental results, and shown how the stimulant action of morphine could lead to a failure of transport of intestinal contents. Recent work by the Schaumanns (Schaumann, Giovannini and Jochum, 1952 ; Schaumann, 1955) and by Kosterlitz and Robinson (1955) has indicated, however, that the action of morphine may be through a depression of nervous mechanisms involved in peristalsis.

The method recently developed for exciting the nervous tissue in the wall of the small intestine (Paton, 1955) offered a suitable means for analysing the activity of morphine further. If electrodes are placed within and without the lumen of a strip of guinea-pig ileum immersed in Krebs solution and current is passed between them, vigorous twitchlike contractions can be obtained to single shocks, which are due to excitation of postganglionic cholinergic nerves. The contractions are reproducible, are antagonized by small doses of atropine, are potentiated by anticholinesterases, and resist ganglion-blocking agents. Further, it has proved possible to measure the output of acetylcholine in response to the excitation of nervous tissue in the wall of the gut.

In this paper the effect of morphine (and related drugs) on the twitch of the intestine and on its acetylcholine output is described.

A short account of some of the results obtained with morphine was given elsewhere (Paton, 1956).

\section{METHODS}

The experiments were all made on strips of guineapig ileum suspended in Krebs solution, bubbled with $95 \% \mathrm{O}_{2}$ and $5 \% \mathrm{CO}_{2}$. Rectangular current pulses usually of $1 \mathrm{msec}$. duration, and of sufficient strength to produce a maximal response to a single shock, were applied to the electrodes; the intraluminal electrode was made the anode. When necessary, repetitive stimulation was used to produce a partially or completely fused tetanus for a period of a few seconds or a minute. The contractions of the gut were recorded either on a smoked drum or by a light inkrecorder. The bath was kept at 35 to $37^{\circ} \mathrm{C}$. The capacity of the bath in which the gut and electrodes were immersed was normally $50 \mathrm{ml}$.

The assay of acetylcholine output was conducted on another strip of guinea-pig ileum treated with $5 \mu \mathrm{g} . / \mathrm{l}$. of neostigmine and $10 \mathrm{mg}$./1. of morphine. As soon as the first observation was made that morphine reduced the output of acetylcholine by the gut, 
the possibility suggested itself that morphine might prevent the violent intermittent spasms of the guineapig ileum which occur when it is exposed even to low concentrations of anticholinesterases, and greatly diminish its usefulness for assay. This proved to be the case, and the intestine sensitized with neostigmine (which appeared more suitable than eserine) and quietened with morphine furnished a very convenient assay method which was used in all subsequent experiments. (A paper describing the method is in preparation.) The experiment consisted of transferring to the assay bath $(7.5 \mathrm{ml}$.) an aliquot of the fluid from the donor bath holding the strip of stimulated intestine. The donor bath fluid contained eserine $10^{-6}$. Sensitivity of the recipient intestine down to $1 \mathrm{ng}$. of acetylcholine added to the bath was easily obtained, and assays could be repeated every $1 \frac{1}{2}$ to $2 \mathrm{~min}$. if required.

The following drugs were employed: acetylcholine chloride; methadone hydrochloride; atropine sulphate ; codeine sulphate ; dihydromorphinone hydrochloride; eserine sulphate; heroin hydrochloride ; histamine phosphate; hyoscine hydrobromide; morphine sulphate; metopon hydrochloride (methyldihydromorphinone hydrochloride) ; neostigmine methylsulphate; pethidine hydrochloride; phenadoxone hydrochloride. The doses are all given in terms of the salt, except histamine, which is given as base.

\section{RESULTS}

The Depression of the Twitch of the Guinea-pig Ileum by Morphine.-Morphine in low doses reduces the twitch of a guinea-pig ileum (Figs. 1, 2, 3, 5, 6, 7, $10,11,13)$. The effect is of relatively rapid onset and reaches a plateau within 1 or $2 \mathrm{~min}$. If the morphine is left in the bath thereafter variable results occur. Sometimes a modest spontaneous recovery takes place (Figs. 2, 3, 10). At other times the block is maintained at its initial level up to 15 to $30 \mathrm{~min}$. After a brief exposure of 1 to $3 \mathrm{~min}$., a fairly rapid recovery takes place after washing out (Figs. 5, 7). But, if the morphine is left in for a substantial length of time, recovery is much slower (Figs. 2, 3); often, immediately after washing out, a temporary recovery is succeeded by a yet deeper depression of the twitch (Figs. 2, 10).

The dose-response curve of the response to morphine is hard to establish because of the development of tolerance as described later. But if doses are spaced $30 \mathrm{~min}$. or an hour apart, and if exposures are only long enough to record the maximum effect, reproducible

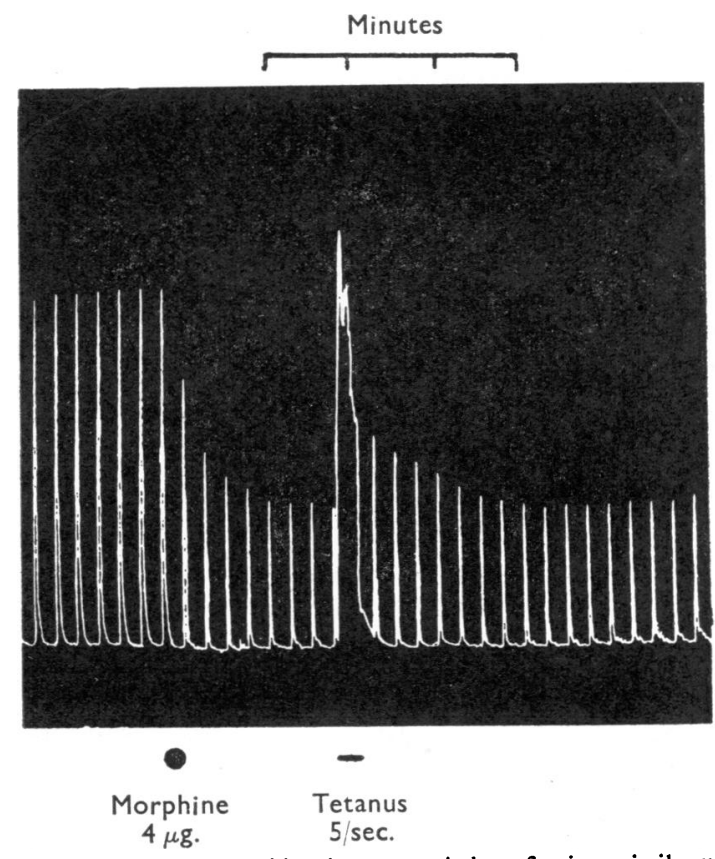

FIG. 1.-Effect of morphine $4 \mu \mathrm{g}$. on twitches of guinea-pig ileum stimulated by single maximal shocks coaxially every 15 sec., and transient partial recovery of twitch after a brief tetanus.

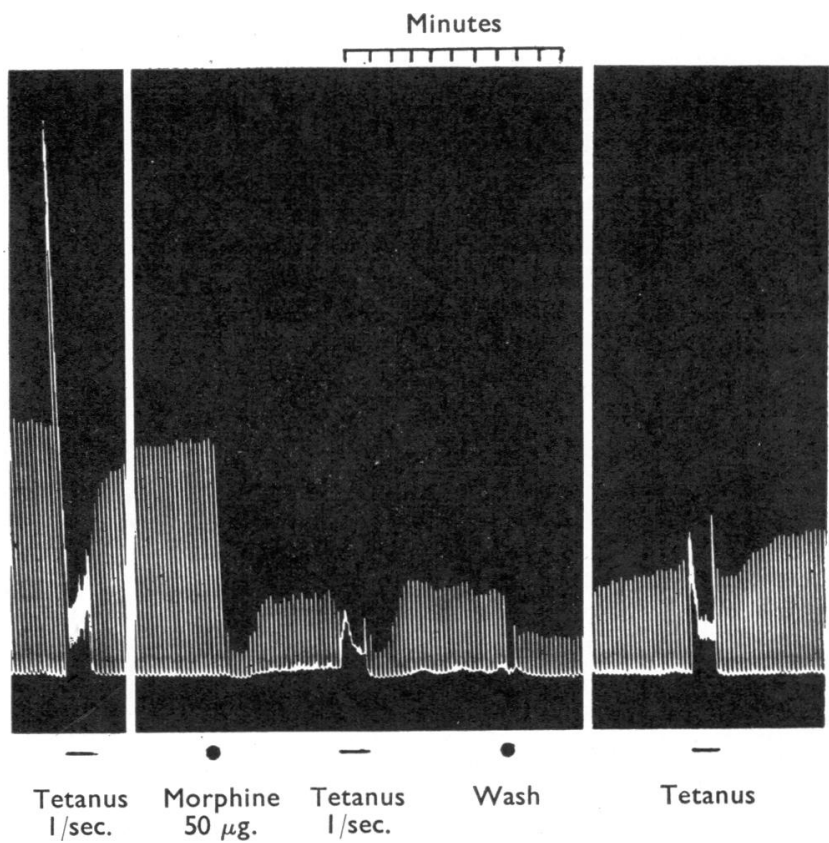

FIG. 2.-Effect of morphine $50 \mu \mathrm{g}$. on twitches $(6 / \mathrm{min}$.) and tetanus $(1 / \mathrm{sec})$ of guinea-pig ileum, showing partial recovery of twitch in presence of morphine, characteristic effect of morphine on shape of tetanic response, further reduction of twitch on washing out morphine, and incomplete recovery $20 \mathrm{~min}$. after washing out morphine. 


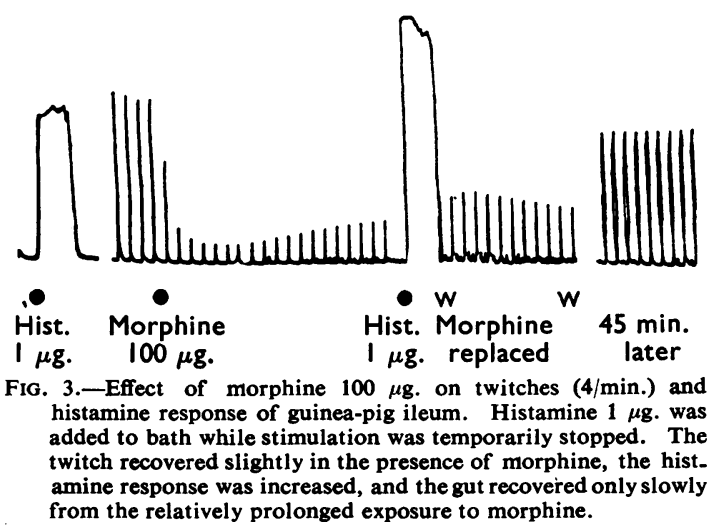

responses to morphine can be obtained. Even then, however, the first response to morphine is often proportionately larger than later responses (Fig. 10). The threshold dose of morphine is about $10^{-8}$; maximal action, in the absence of tolerance, is achieved by about $10^{-6}$ morphine.

Morphine also modifies the tetanic response of the gut to repetitive stimulation. The chief change is that its initial sharp spike is relatively more depressed, and the sustained part of the tetanic response less affected (Fig. 2). After the tetanus the twitch may be reduced (Fig. 2) or partially restored for a short time (Fig. 1).

The depression produced by morphine can be rapidly reversed by anticholinesterases such as eserine or neostigmine in concentrations of $10^{-7}$.

The Effect of Drugs Related to Morphine.-All the drugs tested which possess an analgesic action similar to that of morphine also exerted a depressant effect on the twitch of guinea-pig ileum. Figs. 4, 5, 6, 7, 8 illustrate some typical results with the drugs used. The absolute comparison of potency between one drug and another is difficult to make quantitative, because tolerance develops with them all. But if those responses are selected which were either (1) the result of the first administration of an opiate, or (2) were obtained during a series of small well-spaced doses, or (3) were obtained over a period where tolerance was developing uniformly so that a correction could be made for it, approximate quantitative comparisons can be made which are fairly reproducible. Table I summarizes the estimates of relative potency so obtained. Fig. 9 gives three dose-response curves from three separate experiments,

The activity of a compound on the ileum is well related to its analgesic potency. Thus codeine was relatively ineffective, although with doses of $50 \mu \mathrm{g}$. to $1 \mathrm{mg}$. convincing effects could be produced. On the other hand, phenadoxone, methadone,
TABLE I

APPROXIMATE RELATIVE POTENCY OF MORPHINE-LIKE SUBSTANCES IN BLOCKING THE TWITCH OF THE GUINEAPIG ILEUM

$\begin{array}{lccccc}\text { Phenadoxone } & \ldots & \ldots & \ldots & \ldots & \mathbf{1 0 0} \\ \text { Dihydromorphinone } & \ldots & \ldots & \ldots & \mathbf{7 0} \\ \text { Metopon } & \ldots & \ldots & \ldots & \ldots & \mathbf{5 5} \\ \text { Methadone } & \ldots & \ldots & \ldots & \ldots & \mathbf{3 0} \\ \text { Heroin .. } & \ldots & \ldots & \ldots & \ldots & \mathbf{3 0} \\ \text { Morphine } & \ldots & \ldots & \ldots & \ldots & \mathbf{1 5} \\ \text { Codeine .. } & . & \ldots & . & \ldots & \mathbf{0 . 7}\end{array}$

dihydromorphinone, metopon, and heroin were all more active than morphine.

Pethidine presented a special problem, since it is known to have an atropinic action of its own which would depress the twitch independently of the type of activity here being analysed. But it was found that evidence for a morphine-like action could be obtained in the following way. It had been observed that after atropine the response to injected acetylcholine was reduced considerably more than was the twitch, so that the "acetylcholine-equivalent " of the twitch (the dose which produces a contraction of the same height as the twitch) may increase 5- to 10 -fold. With pethidine, on the other hand, although the response to injected acetylcholine is reduced as the twitch height diminishes, the antagonism to acetylcholine is not great (Fig. 8) and the acetylcholine equivalent of the twitch in fact rises. The effect of pethidine, therefore, is perfectly compatible with that of a drug having a mild atropinic action and a distinct morphine-like effect. The total effect of pethidine on the gut is roughly half as great as that of morphine, so that its specific morphine-like activity must be lower still.

The drugs mentioned all resembled morphine in other ways. The depression by any of these compounds usually comes on fairly quickly, and recovery after washing out is slower with a prolonged exposure, or when a large effect was produced. With all of them tolerance was liable to develop (Fig. 4). The drugs do, however, differ in their time course of action. In general codeine tended to reach its peak action quickest, morphine was usually (but not always) somewhat slower and the other substances tested (especially phenadoxone) had a still slower development of action. Thus, in Fig. 4, phenadoxone exerts the most slowly developing effect ; in Fig. 6, methadone acts more slowly than morphine, though present in more powerful dosage. There was, in short, an inverse relation between potency on the one hand, and speed of onset or offset of action on the other.

Tolerance.- It was mentioned above that the sensitivity of the preparation diminished with repeated large doses. Even with small doses repeated at intervals of about 15 min., sensitivity often declined. In any experiment in which 


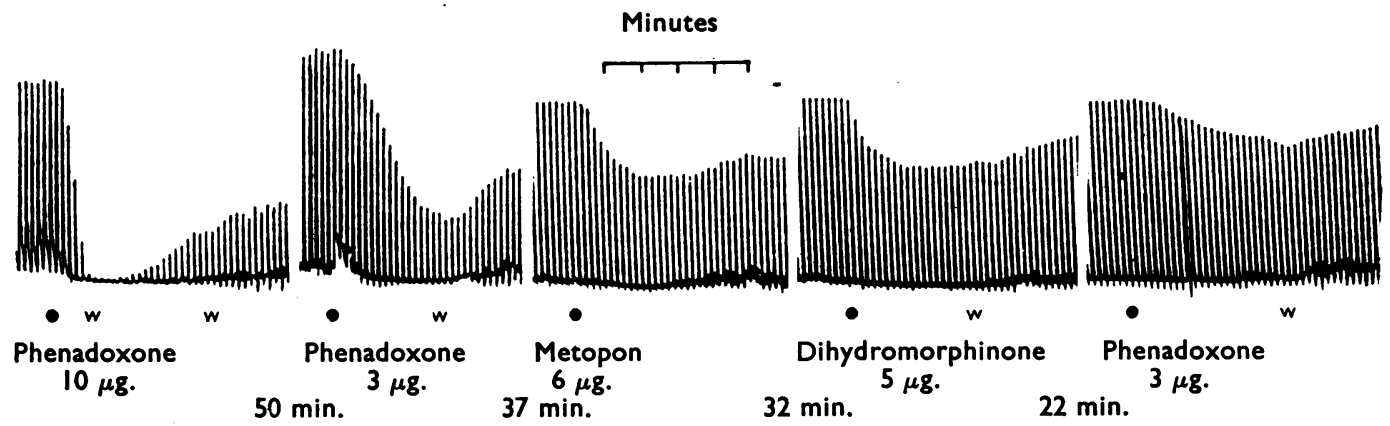

FIG. 4.-Effects of phenadoxone, metopon, an 1 dihydrom $r$ rphinone on twitches $(6 / \mathrm{min}$.) of guinea-pig ileum, showing development of tolerance (compare the two responses to phenadoxone $3 \mu \mathrm{g}$.) and varying rates of onset of action. The times indicated in this and subsequent figures give the interval between doses of opiate.
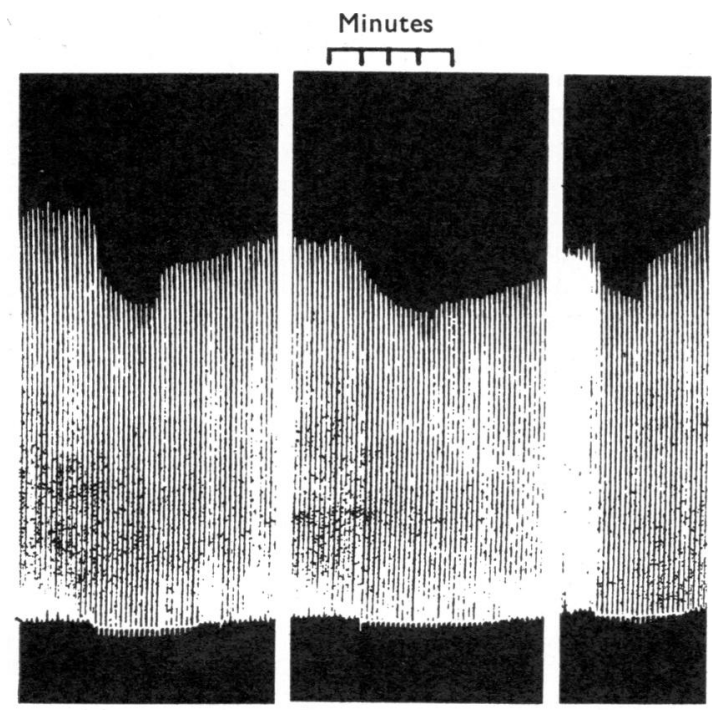
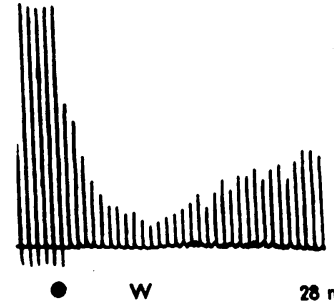

Morphine

$25 \mu \mathrm{g}$.

$28 \mathrm{~min}$.

Methadone

$25 \mu \mathrm{g}$.

FIG. 6.-Effects of morphine $25 \mu \mathrm{g}$. and methadone $25 \mu \mathrm{g}$. on twitches of guinea-pig ileum (6/min.).

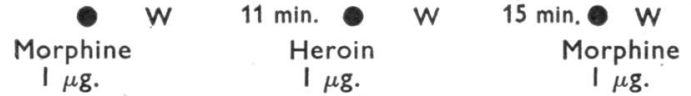

Fig. 5.-Effects of morphine $1 \mu \mathrm{g}$. and heroin $1 \mu \mathrm{g}$. on twitches of guinea-pig ileum (6/min.).

Minutes

Tा Tा
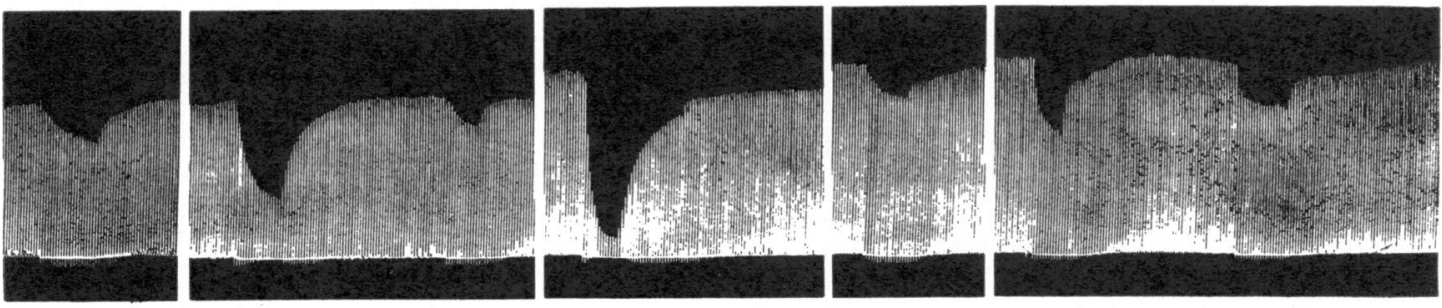

- w
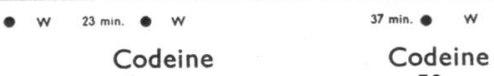

$50 \mu \mathrm{g}$.

$200 \mu \mathrm{g}$.

Codeine

Codeine

$50 \mu \mathrm{g}$.

$15 \min . \quad w$

$2 \mu \mathrm{g}$.

Morphine

w

I $\mu g$.

FIG. 7.-Effect of various doses of codeine and morphine on twitches of guinea-pig ileum $(6 / \mathrm{min}$.) showing how the response varies with dose, and that the first response to codeine $50 \mu \mathrm{g}$. is larger than subsequent ones. 
repeated administrations occurred over a period of hours, the intestine gradually became less sensitive. Sometimes, but not always, recovery of the twitch could be demonstrated despite the continued presence of a dose of morphine; this recovery, however, was never complete (Figs. 2, 3, 10). Although in one experiment tetanic stimulation appeared to accelerate the development of tolerance, this could not be substantiated. In general, the tolerant intestine showed more spontaneous activity than normal, and this was sometimes specially marked on washing out a dose of opiate.

It proved difficult to control the sensitivity of the preparation satisfactorily, and it has not been possible hitherto to devise a reliable method either of avoiding tolerance completely, or of producing it to a known degree. But Fig. 10 illustrates one of the more reproducible phenomena. First of all a small dose of morphine $(50 \mu \mathrm{g}$.) is given. After an interval for recovery $(90 \mathrm{~min}$.), the dose is repeated, producing a nearly comparable effect. Then, without removing this dose, the same dose is administered again; although this total dose is normally adequate to produce a complete block, now it produces no further effect. A much larger dose is likewise ineffective. The depression of the twitch seems to be fixed at a height determined by the effect of the first small dose chosen. If the morphine is now washed out the twitch height (sometimes after a transient recovery) is reduced still further and only slowly recovers. In order to restore the twitch height rapidly to its previous level, the simplest procedure at this stage is to add morphine ; a total of $10 \mathrm{mg}$., sufficient to produce a short-lived contraction of the gut, has to be applied before the twitch height corresponds to its original level. Removing the morphine again leads to a reduction of the twitch. It is possible, in this way, to convert the preparation from a state in which a small dose of morphine depresses its contraction, to a state in which the intestine is dependent on the presence of morphine to maintain its normal response. The phenomenon of "tolerance" could not be produced with hyoscine or atropine. If these are given repeatedly their action on this preparation never decreases, and often increases slightly owing to the difficulty of washing the atropine out completely. Atropine continues to be normally active in gut which has been fully desensitized to morphine.

The Action of Nalorphine.-When the possibility of antagonism between nalorphine and morphine is tested, nalorphine proves to have itself a depressant effect on the intestine (Fig. 11).

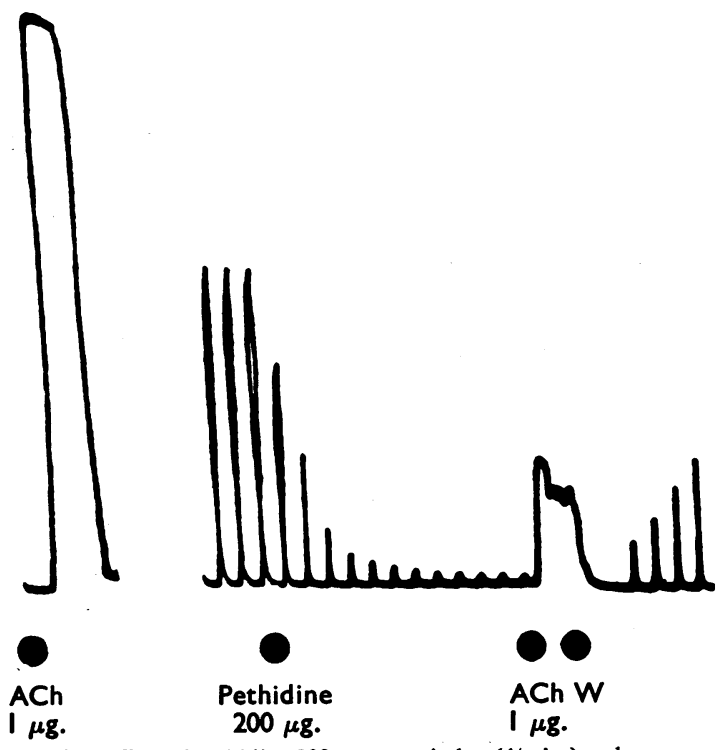

FIG. 8. -Effect of pethidine $200 \mu \mathrm{g}$. on twitches (4' $\mathrm{min}$.) and response to acetylcholine $1 \mu \mathrm{g}$. by guinea-pig ileum.

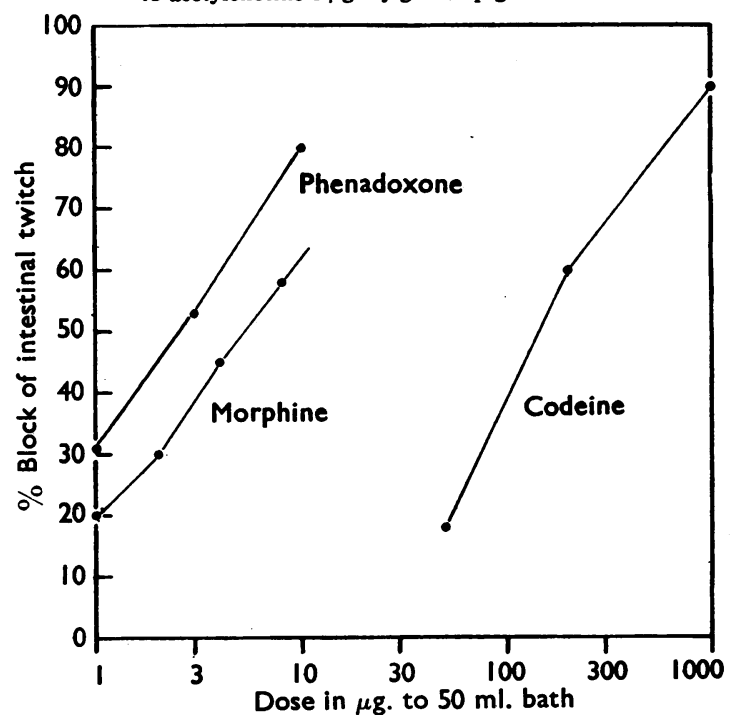

FIG. 9.-Dose-response relation for the reduction, by phenadoxone morphine and codeine, of the twitch of guinea-pig ileum.

This is exerted in small doses and made the demonstration of an antagonism correspondingly complicated. It is possible, by giving a large dose of nalorphine and allowing the intestine to recover from it, to show that morphine had less effect thereafter. But the same effect is produced by a large dose of morphine. Further, acute tolerance to nalorphine can be produced in just the same way as to morphine (Fig. 12). The two drugs could not, in fact, be distinguished qualitatively, in 


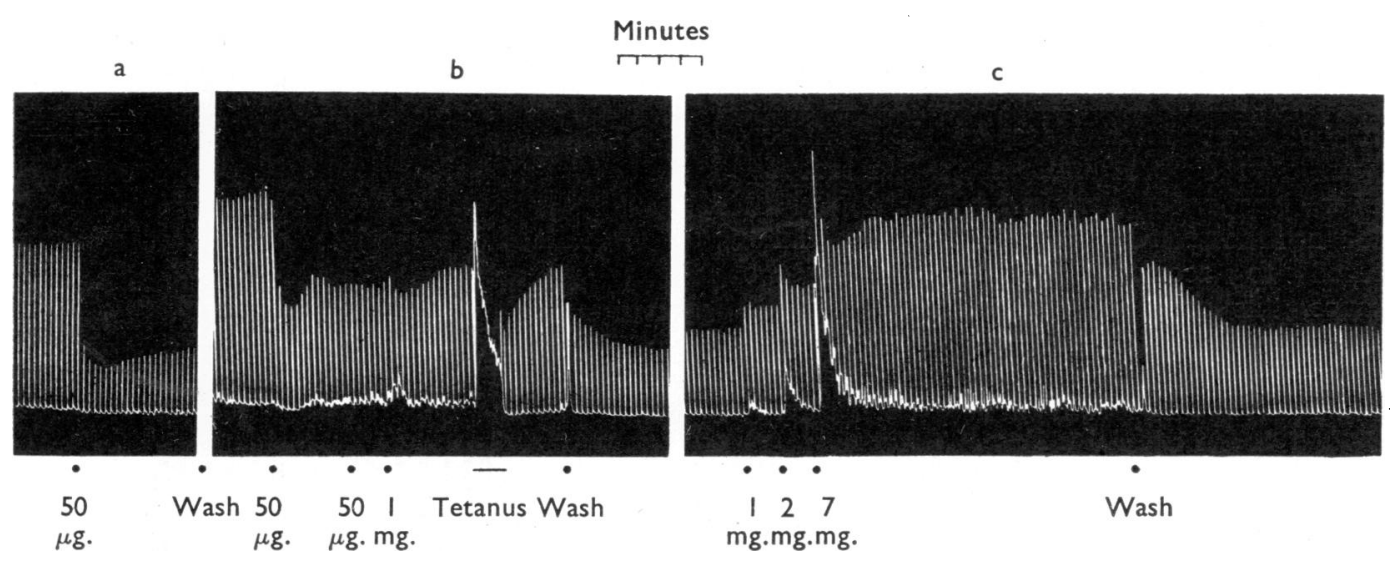

Fio. 10.-Development of "acute tolerance" and "morphine dependence" by guinea-pig ileum. Doses shown are of morphine. Twitches $4 / \mathrm{min}$.; tetanus $5 / \mathrm{sec}$. Between $(a)$ and $(b) 88 \mathrm{~min}$.; between $(b)$ and $(c) 22 \mathrm{~min}$. See text for other details.

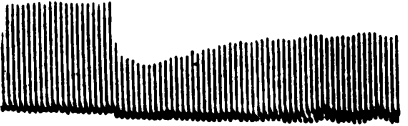

-

Morphine $30 \mu \mathrm{g}$.

FIG. 11.-Effect of morphine $30 \mu \mathrm{g}$. and nalorphine $10 \mu \mathrm{g}$. on twitches of

guinea-pig ileum (6/min.).

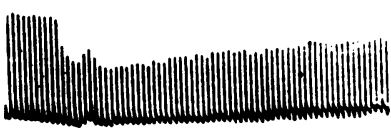

$\bullet$

Nalorphine $10 \mu \mathrm{g}$.
Minutes

a
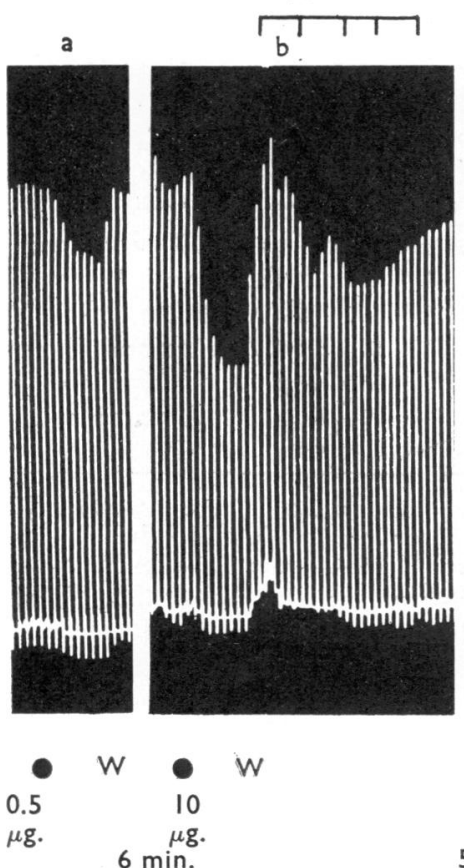

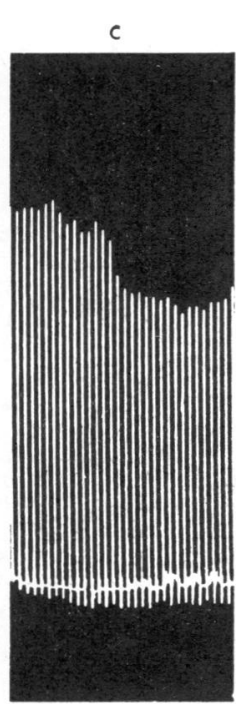

Fig. 12.-Development of "acute tolerance" to nalorphine. (a) Effect of $0.5 \mu \mathrm{g}$. nalorphine; (b) effect of $10 \mu \mathrm{g}$. nalorphine (c) effect of $0.5 \mu \mathrm{g}$. nalorphine, followed by additions of $10 \mu \mathrm{g}$. and $1 \mathrm{mg}$. nalorphine. Twitches $6 / \mathrm{min}$. respect of their ability to depress the gut or to make it resistant to opiates. The results so far obtained suggest that on the intestine nalorphine should be regarded as an analogue rather than as a specific antagonist to morphine, although the experiments do not exclude that tolerance can be produced more rapidly with nalorphine.

The Analysis of the Action of Morphine.-The depressant action of morphine on the twitch of the intestine cannot be due to any local anaesthetic effect, such as cocaine displays. The threshold for maximal excitation was not changed by morphine and brief stimuli remained effective. When tested on frog sciatic nerve, stripped of its sheath, morphine in concentrations up to $10^{-2}$ failed to block nervous transmission (J. W. Thompson; personal communication).

If nervous tissue is normally responsive in the presence of morphine, then the reduction of the twitch height must be due to a reduction of acetylcholine output from the nerve endings, or to a competitive antagonism to the acetylcholine at the receptor groups, or a direct effect on the muscle itself. The first test to distinguish these possibilities was made by comparing the response to stimulation with the response to injected acetylcholine, in the presence of morphine. Fig. 13 shows a typical experiment. The twitch could at first be matched against a dose of $1.2 \mu \mathrm{g}$. of acetylcholine added to the bath. When morphine was given, the twitch was greatly reduced, but the response to acetylcholine was unaltered. Similar results were obtained with heroin and codeine. It was also found that sometimes the response to histamine was in fact augmented by morphine (Fig. 3). 


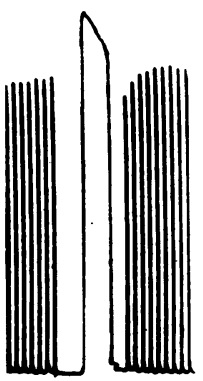

$\mathrm{ACh}$

1.2

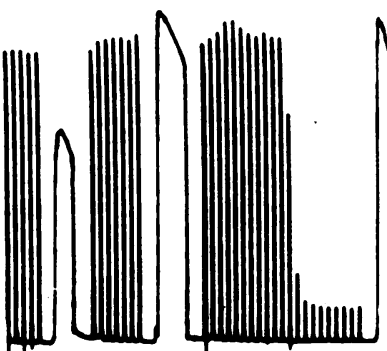

$\mathrm{ACh}$

1.0
$\mathrm{ACh}$

1.2

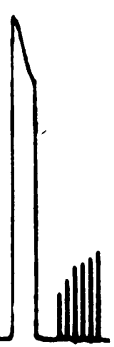

Morph. ACh $100 \mu \mathrm{g}$.

\section{2}

FIG. 13.-Comparison of the effect of morphine on the twitch of the guinea-pig ileum $(6 / \mathrm{min}$.) with its effect on the response to acetylcholine $1.2 \mu \mathrm{g}$. After each injection of acetylcholine the bath was washed out.
These results exclude the possibility that morphine either antagonizes acetylcholine after release or impairs in any way the contractile ability of the muscle. One must, therefore, suppose that morphine reduces the output of acetylcholine by the nerve endings. This was put to the test by assaying the acetylcholine output from a piece of intestine in the presence of eserine. Results obtained on the output of acetylcholine are shown in Fig. 14 and Table II. Fig. 14 gives part of an assay showing the reduction of the acetylcholine output by the presence of morphine in a concentration of $4 \times 10^{-7}$. Table II summarizes the effects of morphine on the output of acetylcholine at various frequencies, in three other experiments. In each of these, the output due to stimulation has been obtained by subtracting the resting output,

TABLE II

OUTPUT OF ACETYLCHOLINE FROM STIMULATED GUINEA-PIG ILEUM AT VARIOUS RATES OF STIMULATION, AND THE EFFECT OF MORPHINE

(ng./shock, corrected for resting output)

\begin{tabular}{|c|c|c|c|c|c|c|c|c|c|}
\hline \multirow[b]{2}{*}{$\begin{array}{l}\text { Rate of stimulation .. } \\
\text { Control } \ldots \\
\text { * Morphine treated } \ldots\end{array}$} & \multirow[b]{2}{*}{$\begin{array}{l}. \\
\cdots \\
\cdots\end{array}$} & \multirow{2}{*}{$\begin{array}{c}(a) \\
50 / \min . \\
0 \cdot 25 \\
0.034 \\
\left(10^{-6}\right)\end{array}$} & \multicolumn{3}{|c|}{ (b) } & \multicolumn{4}{|c|}{ (c) } \\
\hline & & & $\begin{array}{c}1 / \mathrm{sec} . \\
0.11 \\
\left(2 \times 10^{-6}\right)\end{array}$ & $\begin{array}{c}6.6 / \mathrm{sec} \\
0.049 \\
0.050 \\
\left(2 \times 10^{-6}\right)\end{array}$ & $\begin{array}{c}27 / \mathrm{sec} . \\
0.044 \\
0.042 \\
\left(2 \times 10^{-6}\right)\end{array}$ & $\begin{array}{c}3 \frac{1}{2} / \mathrm{min} \\
0.40 \\
\left(4 \times 10^{-6}\right)\end{array}$ & $\begin{array}{c}20 / \mathrm{min} . \\
0.16 \\
0.062 \\
\left(4 \times 10^{-6}\right)\end{array}$ & $\begin{array}{c}1 / \mathrm{sec} . \\
0.11 \\
0.095 \\
\left(4 \times 10^{-6}\right)\end{array}$ & $\begin{array}{c}5 / \mathrm{sec} \\
0.075 \\
0.067 \\
\left(4 \times 10^{-6}\right)\end{array}$ \\
\hline
\end{tabular}

* Morphine concentration is given by the numerals in brackets.

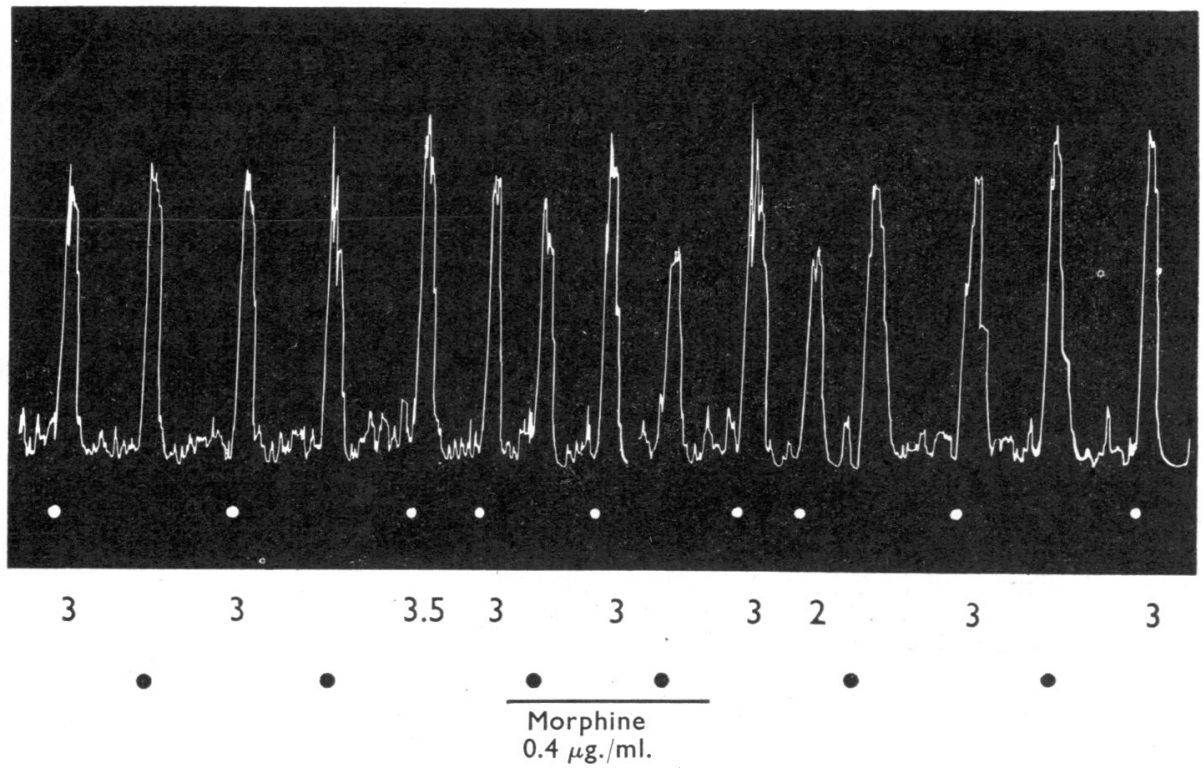

FIG. 14.-Reduction of acetylcholine output from stimulated eserinized guinea-pig ileum by morphine; part of the assay on another strip of ileum. Standard acetylcholine injections marked by white dots. Samples of fluid from donor bath (0.3 $\mathrm{ml} .=1 / 25$ total donor bath volume) during continuous stimulation at $5 / \mathrm{sec}$., marked by black dots ; successive samples taken every 3 min., the donor bath being then immediately and rapidly washed out. When morphine $0.4 \mu \mathrm{g} . / \mathrm{ml}$. was added to donor bath, the acetylcholine equivalent of sample fell from $3 \mathrm{ng}$. to $\mathbf{2} \mathrm{ng}$. After removing morphine, the acetylcholine equivalent returned to control level. 
separately determined, from the total output observed. It will be seen here, as will be discussed more fully in another paper, that the normal output of acetylcholine decreases as the repetition frequency of the stimulus increases. But the effect of morphine is such as to reduce the acetylcholine output to an approximately constant low amount. Thus the proportionate reduction of acetylcholine output is greater on the slow rates of stimulation than on the rapid. It appears as though there were a morphine-susceptible quantum of acetylcholine output, together with an irreducible quantum which morphine cannot touch.

Morphine reduces the resting output by 20 to $40 \%$; thus in three experiments the output fell from 2.7 to $1.5,1.7$ to 1.4 , and 1.2 to 0.8 $\mathrm{ng}$./min. respectively, in the presence of morphine in concentrations from $10^{-6}$ to $4 \times 10^{-6}$. It was also found, however, that sometimes the resting output increased above its initial level after the morphine was washed out; in the most striking case, the resting output, after stimulation for $20 \mathrm{~min}$. at $5 / \mathrm{sec}$. in the presence of morphine $2 \times 10^{-6}$, rose to $3.2 \mathrm{ng} . / \mathrm{min}$., from a control value of $1.1 \mathrm{ng} . / \mathrm{min}$.

It may be questioned whether the reduction of output of acetylcholine achieved by morphine is sufficient to produce failure of neuromuscular transmission in the intestine. It has already been stated that the output of acetylcholine/shock can be reduced in another way, by stimulating the intestine more rapidly. If this is done in the uneserinized preparation the twitch height begins to fall below its normal level at rates of about 20/ min., and falls further as faster rates are applied. Combining this result with those of Table II, it may be estimated that failure of transmission will begin when the output falls below about a value of the order of $0.2 \mathrm{ng}$./shock. It is clear from the same table that morphine can reduce the output far below these levels.

It appears, therefore, that the action of morphine can be satisfactorily explained by a depression of acetylcholine output by it. But if acetylcholine output is depressed in this way one might expect that a similar depression of output could be obtained at other cholinergic synapses, such as the junction of motor nerves with striated muscle, or in autonomic ganglia. Accordingly the effect of morphine on acetylcholine output from the perfused ganglion was examined. - It was found, however, as Hebb and Konzett (1949) reported, that morphine does not depress ganglionic transmission except in very large doses; indeed its first action is to potentiate the effects of preganglionic stimulation. In addition, a dose of $1 \mathrm{mg}$. injected into the arterial perfusion cannula had no effect on acetylcholine output. Similarly a test of morphine on the neuromuscular junction showed that it has singularly little neuromuscular effect; it required $5 \mathrm{mg}$. morphine given by close-arterial injection into the tibialis muscle of the cat to produce a very transient reduction of the twitch to sciatic nerve stimulation. It is clear, therefore, that the action of morphine is not exerted at all cholinergic synapses; the experiment on the ganglion serves to show, however, that when acetylcholine output is not depressed, transmission is not impaired.

\section{Discussion}

These experiments show that morphine, in low concentrations, has a depressant action on the postganglionic cholinergic nerve fibres of the guineapig intestine, reducing both the resting output of acetylcholine and the output from the nerveendings when they are stimulated. In these concentrations, morphine did not stimulate the gut, nor interfered with its contractile power, nor lessened its sensitivity to acetylcholine. On this preparation, therefore, the action of morphine was exerted only on the nervous tissue and not on the smooth muscle. The work reported by Schaumann et al. (1952) and Schaumann (1955), using a different method, points to the same conclusion. Schaumann et al. showed that a number of strong analgesics could depress the peristaltic reflex of the guinea-pig ileum ; and this was followed by the demonstration (Schaumann, 1955) that morphine could paralyse the preparatory phase of the peristaltic reflex; this phase of the reflex resists ganglion-blocking agents, but is sensitive to atropine, and so presumably involves postganglionic cholinergic nerve fibres. Kosterlitz and Robinson (1955) have confirmed these observations, and found in addition that morphine has an inhibiting effect on the action of 5-hydroxytryptamine, whose action on the ileum is now believed to involve a nervous pathway (Robertson, 1953 ; Rocha e Silva, Valle and Picarelli, 1953 ; Gaddum and Hameed, 1954).

No obvious reason can yet be advanced why this action of morphine is exerted on cholinergic nerve fibres in the intestine, but not on those of the autonomic ganglion or neuromuscular junction of striated muscle. It may be, indeed, that the action concerned is not one specifically on acetylcholine output, but that morphine has some other effect at the terminations of postganglionic nerves, which results in a failure of normal nerve terminal activity. Kosterlitz and Robinson (1955) suggest 
that morphine may act on the interstitial cells of Cajal. This possibility cannot, at present, be tested by direct experiment. The failure of morphine to reduce the response of the gut to acetylcholine directly injected must exclude, on this theory, any rôle of the interstitial cells in the response of the gut to acetylcholine once it is free in the tissue spaces. If the action of morphine is to depress acetylcholine output, then the hypothesis would require that the interstitial cells were involved in the process of acetylcholine output. The postganglionic axones seem far the most likely source of acetylcholine, but it is not impossible that the interstitial cells serve as " moderators" of the nerve-terminal acetylcholine release.

The notion that morphine can act directly on the local nervous apparatus of the intestine, already proposed by Schaumann et al., is relatively novel, and it probably cannot explain all the intestinal actions of morphine in the whole animal. It contributes only to a failure of propulsion by the intestine, together with any secondary results of such failure. But the spasmogenic action of morphine in the whole animal, distinct though possibly overestimated, must receive some other explanation, either by direct action on smooth muscle in some species, or by some central stimulant action with a visceral efferent component. Two other processes might contribute to an increased activity of the intestine after morphine, although they can hardly account for all of the results reported. In the first place, morphine is a histamine-liberator (Feldberg and Paton, 1951; Evans, Nasmyth and Stewart, 1952), and it is known that histamine-liberators can increase the motility of the intestine, although only with large doses can a frank contraction be produced (Feldberg and Smith, 1954). Secondly, in the experiments reported above, it was noticed that sometimes, following a sustained exposure to morphine, and after the morphine was washed out, the resting acetylcholine output increased; whether this represented an increased leakiness of the cholinergic nerve endings, or a change in the output of acetylcholine from non-nervous sources, it may contribute to the enhanced though rather incoordinate motility of the gut produced sometimes by morphine administration.

All the analgesics tested had a morphine-like action. An important point was that those compounds more active than morphine as analgesics were also more active against the intestinal twitch ; and those less potent as analgesics were less active.
This parallelism naturally suggests that the guineapig intestine provides a test-object for analgesics with closer analogies to the central nervous system than might be expected. This is borne out by a number of other observations. First, the concentrations of morphine required for activity compare well with those used therapeutically; the threshold concentration for a distinct effect on the ileum was about $10 \mathrm{ng} . / \mathrm{ml}$.; a dose, clinically, of $\frac{1}{4}$ grain to a subject weighing $75 \mathrm{~kg}$. would, if dissolved in the whole body, give a concentration of $200 \mathrm{ng} . / \mathrm{ml}$., but lower concentrations probably exist in practice. Secondly, tolerance of the intestine to morphine could be readily produced, such that very large increments of morphine dosage produced dwindling actions. It was even possible to produce a state which could be interpreted as "morphine-dependence," whereby withdrawal of morphine from a tolerant strip of intestine would reduce its contraction in response to nervestimulation, and replacement of morphine restored it. Third, it is worth noting that the proportionate effect of morphine is less as the rate of excitation of the nerves is increased. This may well correspond to the clinical impression that severe pain can break through morphine analgesia.

It is striking how far the nervous system of the gut, the most nearly " autonomic" of all the peripheral nervous tissue, corresponds in its reactions to those of the central nervous system ; and it suggests that the enteric autonomic network furnishes a valuable simple paradigm of the far more complicated networks of the brain itself.

\section{REFERENCES}

Evans, A. O. J., Nasmyth, P. A., and Stewart, H. C. (1952). Brit. J. Pharmacol., 7, 542.

Feldberg, W., and Paton, W. D. M. (1951). J. Physiol., 114,490 . and Smith, A. N. (1954). Ibid., 124, 219.

Gaddum, J. H., and Hameed, K. A. (1954). Brit. $J$. Pharmacol., 9, 240.

Hebb, C. O., and Konzett, H. (1949). Nature (Lond.), 163, 720.

Kosterlitz, H., and Robinson, J. A. (1955). J. Physiol., $129,18 P$.

Paton, W. D. M. (1955). Ibid., 127, 40P.

(1956). Abstr. 20th int. physiol. Congr., Bruxelles, 708. Robertson, P. A. (1953). J. Physiol., 121, 54P.

Rocha e Silva, M., Valle, J. R., and Picarelli, Z. P. (1953). Brit. J. Pharmacol., 8, 378.

Schaumann, O., Giovannini, M., and Jochum, K. (1952). Arch. exp. Path. Pharmak., 215, 460.

Schaumann, W. (1955). Brit. J. Pharmacol., 10, 456.

Vaughan Williams, E. M., and Streeten, D. H. P. (1950). lbid., 5, 584.

_L (1951). Ibid., 6, 263. 